\title{
Cobrança pela Drenagem Urbana de Águas Pluviais: Bases Conceituais e Princípios Microeconômicos
}

\author{
Vanessa Cançado, Nilo de Oliveira Nascimento e José Roberto Cabral \\ UFMG - Departamento de Engenharia Hidráulica e Recursos Hidricos - niloon@ehr.ufmg.br
}

Recebido: 14/07/05 - revisado: 26/09/05 - aceito: 18/11/05

\section{RESUMO}

Em um cenário de crescente restrição orçamentária do setor público, novas formas de custeio dos serviços de drenagem urbana das águas pluviais são discutidas. Como alternativa ao tradicional financiamento por meio de impostos sobre propriedade, surge a possibilidade de uma cobrança individualizada dos serviços via taxa de drenagem. Esta poderia implicar em ganhos de justiça tributária e eficiência alocativa. Mas as peculiaridades econômicas da drenagem urbana, ofertada em regime de monopólio natural e com características de bem público, dificultam a individualização do débito. Este artigo, em uma abordagem teórico-conceitual, discute estas peculiaridades, a viabilidade de criação da taxa à luz da teoria econômica e qual a metodologia tarifária mais adequada para este fim.

Palavras-Chave: drenagem pluvial, taxa de drenagem, cobrança

\section{INTRODUCÃO}

Nos debates que envolvem a drenagem urbana, a dimensão econômico-financeira assume importância. Discutem-se não apenas novas tecnologias, minimizadoras de custo e de impactos ambientais, mas também formas alternativas no custeio dos serviços. O financiamento via Tesouro municipal, principalmente por meio do Imposto sobre Propriedade Territorial Urbana - IPTU, esbarra na restrição orçamentária do setor público, onde a drenagem pode não ser percebida como prioridade política. Ganham ênfase os possíveis benefícios da criação de uma taxa sobre os serviços como forma de garantir os investimentos necessários ao setor. Embora a sua adoção tenha complicadores pelas características da oferta e demanda no setor, existem ganhos de eficiência alocativa quando a cobrança está relacionada com o consumo individual pelos serviços. A taxa possibilita uma distribuição socialmente mais justa dos custos ao onerar mais os usuários que utilizam mais o sistema.

Este artigo apresenta as bases conceituais e princípios microeconômicos que podem orientar uma forma alternativa de financiamento da drenagem urbana das águas pluviais: a cobrança individualizada pelos serviços. Em uma primeira parte são apresentadas as características econômicas dos serviços, onde se discutem oferta, demanda, externalida- des e a questão do valor na drenagem urbana. Estas características orientam a base metodológica para criação de uma taxa de drenagem, assunto discutido na seção seguinte. Nesta são apresentadas várias metodologias tarifárias e determinada a que melhor se ajusta a uma taxa de drenagem. Por último são mostradas a conclusão e referências do trabalho.

\section{CARACTERÍSTICAS ECONÔMICAS DOS SERVIÇOS DE DRENAGEM URBANA}

Bem público e monopólio natural

Os mecanismos de mercado que regulam os bens e serviços privados não funcionam adequadamente para os serviços de drenagem urbana. Isto porque estes possuem características de bens públicos, como a não excludência e a não rivalidade. Portanto, não é possível excluir um agente de seu consumo: quando oferecido os serviços, todos podem ou vão obrigatoriamente consumi-los (não excludência). Além disso, nos limites do sistema, a demanda de um usuário não afeta a disponibilidade de outros (não rivalidade). Sua oferta é feita em regime de monopólio natural: há um único ofertante dos serviços e este apresenta custos médios decrescentes ao longo do intervalo relevante de pro- 
dução, em outros termos, economias de escala até o limite da capacidade.

Estas características implicam em um comportamento econômico diferenciado daquele dos bens ou serviços privados. Algumas peculiaridades relacionadas à oferta, demanda, produção de externalidades e determinação do valor dos serviços são mostradas a seguir.

\section{Características de oferta}

O dimensionamento dos sistemas de drenagem ocorre por meio de avaliação hidrológica e hidráulica. A estimativa de cenário futuro de impermeabilização ou a impermeabilização máxima prevista em legislação municipal é utilizada como parâmetro nestas avaliações.

A partir deste dimensionamento, a rede de drenagem é implantada e os serviços disponibilizados à população. Eles são oferecidos na mesma "quantidade" para todos os beneficiários. Os indivíduos podem avaliar a drenagem de maneira desigual ou terem diferentes participações na demanda agregada dos serviços por meio da propriedade dos terrenos e impermeabilização dos mesmos, mas todos têm disponíveis a mesma quantidade para consumo. São indivisíveis na ótica da oferta, mas divisíveis na perspectiva da demanda.

Como ocorre com freqüência nos serviços públicos, a provisão da drenagem urbana envolve custos fixos elevados, essencialmente os investimentos na implantação das redes de drenagem, com longo prazo de maturação, e custos marginais pequenos, quase nulos. Nestas condições, um preço de eficiência econômica, aquele que se iguala ao custo marginal dos serviços, pode não ser capaz de cobrir os custos de implantação e operação do sistema: o custo marginal tende a ser menor do que o custo médio. O ideal microeconômico de que a receita com a venda de uma unidade adicional de produto seja igual ao valor dos recursos que foram utilizados para produzi-la não permite a viabilidade financeira do empreendimento.

Como solução, a tendência é que a administração pública (o regulador) defina um preço que permita o ponto de equilíbrio para a prestadora: produzir em um nível onde o preço se iguale aos custos médios de produção.

\section{Características de demanda}

Quando ocorre a demanda pelos serviços de drenagem urbana? Quando é lançado no sistema de drenagem o escoamento superficial gerado no am- biente urbano (Debo \& Reese, 1995:11). Cada proprietário de imóvel urbano é um consumidor deste sistema, e sempre que ele aumenta a área impermeabilizada de sua propriedade, gera demandas extras pelo serviço. Ressalte-se que a drenagem urbana é um bem essencial. Embora alguns o utilizem mais ou menos, é impossível deixar de usufruí-lo.

A grande variabilidade na intensidade, duração e freqüência das precipitações reflete em uma "demanda" estocástica pela drenagem com grande variação ao longo do tempo (durante o ano, o mês, o dia e até mesmo a hora). Em conseqüência, o sistema é dimensionado para operar freqüentemente com capacidade ociosa.

Normalmente bens e serviços essenciais, sem substitutos e que são ofertados por um único prestador apresentam demanda inelástica em relação ao preço: preços maiores não afetam significativamente as quantidades consumidas. Esta inelasticidade ocorre na drenagem urbana e é predominante nos serviços de infra-estrutura. Ela é uma das principais variáveis utilizadas na regulação de preços das empresas de utilidade pública para garantir o equilíbrio de interesses entre ofertante (aumentar o lucro) e usuários (diminuir o pagamento).

Apesar da inelasticidade, é possível que a cobrança específica pelo uso dos sistemas de drenagem leve ao uso mais "racional" do solo urbano - ou a uma maior consciência do impacto daquela propriedade nos custos envolvidos na drenagem - do que a cobrança via impostos gerais. Uma das principais funções da taxa ou tarifa é exatamente fazer esta ligação entre oferta e demanda. Ademais, presume-se a existência de alguma sensibilidade, ainda que pequena, da demanda em relação a variações na taxa sobre os serviços.

\section{Externalidades}

Externalidades são efeitos econômicos colaterais de um processo de produção ou consumo que não são considerados na formação de preço de mercado do produto (Lanna, 2001). São efeitos que interferem no consumo das pessoas ou na produção das firmas, porém de difícil quantificação pela não existência de um mercado para eles.

O sistema de drenagem pluvial é um grande produtor de externalidades, negativas e positivas. A alteração de regimes hidrológicos, assoreamento, poluição de corpos d'água, presença de metais pesados na água são exemplos de externalidades negativas. Como exemplos positivos, o emprego de bacias de detenção com o desenvolvimento de áreas verdes e terrenos para esporte e os efeitos benéficos da 
drenagem sobre a saúde da população (Baptista \& Nascimento, 2002:35).

\section{O valor nos serviços de drenagem urbana}

Os mecanismos de mercado não funcionam bem na alocação dos bens públicos. Os consumidores não podem comprar quantidades ou qualidades diferentes do bem ou serviço público, por exemplo, de uma praça ou de segurança pública: de algum forma, eles (ou a administração pública ou o prestador) têm que decidir a viabilidade da oferta de determinado serviço público, em que nível deve ser oferecido e com quais características qualitativas. Para isto a análise do valor é fundamental.

Existem principalmente três classes de valor associadas aos bens e serviços (Lanna, 2001; Daun \& Clark, 2000): valores de uso, valores de opção de uso e valores de existência. A primeira refere-se aos benefícios adquiridos com o uso físico do bem. Por exemplo, nadar em um rio, práticas de lazer em um parque e a Floresta Amazônica enquanto fonte de madeiras nobres. $\mathrm{O}$ valor de uso não possui uma relação direta com o valor de troca. Um bem pode ser essencial, mas não ser "vendável", não ter ninguém disposto a pagar por ele. A atmosfera é um exemplo. Geralmente, o valor de troca está associado a uma situação de escassez do bem. A água, antes percebida como abundante e de livre acesso, sem valor econômico, hoje é considerada bem escasso. Por isso o atual debate sobre formas de avaliar o seu valor de troca e precificá-la.

O valor de opção de uso relaciona-se ao uso potencial de um bem. Há um certo desconhecimento do seu valor de uso corrente, mas se espera o seu conhecimento futuro e de que ele seja relevante. A percepção deste valor está presente nas estratégias de preservação ambiental: a Floresta Amazônica, por sua diversidade biológica, pode vir a ser uma grande fonte de medicamentos.

O valor de existência ou de não-uso ocorre pela própria existência do bem, independente de sua utilização física. Sua presença e imagem já lhe conferem valor. Ele está ligado a aspectos afetivos, psicológicos ou ambientais: parentes, amigos, pessoas em geral, patrimônio histórico, preservação ambiental etc.

As três classes de valor existem nos serviços de drenagem. O valor de uso é claro pela necessidade de se drenar o escoamento gerado pela impermeabilização do solo. As possíveis externalidades positivas geradas pelo sistema agregam mais valor aos serviços, de uso e de não uso. Uma alternativa local, como a construção de bacia de detenção, po- de gerar valores sociais relevantes, como áreas para lazer e beleza ambiental, com aumento do bem estar da população. Por outro lado, a canalização de um córrego pode ser adequada sob uma ótica privada, mas originar problemas ambientais. É possível agregar valor a uma área, construindo medidas que minimizem as inundações locais, mas diminuir valores a jusante, transferindo o problema da enchente para outra região.

No caso de bens privados transacionados via mercado a determinação do valor (de troca) não é muito problemática. Em função de suas necessidades, preferências e capacidade de pagar, as pessoas decidem individualmente as quantidades consumidas de determinado bem e serviço. Supostamente maximizam a utilidade que encontram no consumo dessas quantidades conforme permitem os seus orçamentos. Cada consumidor, ao resolver o quanto comprar dos vários bens e serviços, leva a um padrão geral de consumo de eficiência econômica, a um nível "ótimo" de consumo e oferta dos bens. A hipótese central desta teoria é de que o consumo de um indivíduo não afeta a utilidade das outras pessoas, o que pressupõe a inexistência de externalidade de consumo.

Nos serviços com características de bem públicos, como a drenagem urbana, tal processo de definição de valor ocorre de maneira diversa. Apesar de cada indivíduo perceber os valores de maneira diferente, portanto avaliar os bens de maneira diferente, suas utilidades estão inexoravelmente ligadas, uma vez que todos são obrigados a dispor do mesmo nível de bem. Neste caso, os mecanismos de mercado dificilmente funcionam na definição de sua provisão eficiente.

Esta situação é exemplificada por Variam (1997): existem três colegas de quarto, um fumante e dois não fumantes. A quantidade de fumaça seria um bem público e os não fumantes reivindicam o direito ao ar puro. $\mathrm{O}$ fumante pode propor que eles troquem um pouco do ar puro por uma compensação financeira. Surgem dilemas: os não fumantes têm que concordar entre si o quanto dessa fumaça seria permitida e qual deveria ser a compensação. Os dois colegas podem possuir preferências e recursos muito diferentes, um pode ser mais sensível ou mais rico do que o outro. Extrapolando-se este exemplo para uma região percebem-se as dificuldades para um acordo sobre o valor e o nível adequado de um bem público. Qual deveria ser a poluição permitida em um rio? Como o poluidor poderia compensar a sociedade por ter diminuído a qualidade da água? Qual deve ser o nível de preservação ambiental? Qual deve ser o período de retorno utili- 
zado no dimensionamento de um sistema de drenagem? Quais são os custos e benefícios sociais de se implantar um sistema de drenagem que preserve o córrego e seu entorno em relação a outro que o canalize e permita a exploração imobiliária à sua margem? Qual dos sistemas irá gerar mais valor?

Estas são questões difíceis de serem respondidas exatamente porque envolvem externalidades e bens públicos. A prática tem sido a utilização de alguns mecanismos extramercados para valoração dos bens públicos. São os chamados métodos observados e hipotéticos diretos ou indiretos. Por meio destes, utiliza-se o mercado de bens privados para inferir sobre o valor de determinado bem público ou cria-se um mercado hipotético para o bem que se aproxime ao máximo de um mercado real. Para isto, métodos como avaliação contingente e de preços hedônicos ganham relevância. Na avaliação contingente é criado um mercado hipotético em um processo de entrevista individual onde o indivíduo declara ou indica sua disposição a pagar pelo bem público inserido neste mercado (DAP) ou, alternativamente, a disposição a aceitar um pagamento compensatório pela renúncia de determinado nível do bem (DAA). Sua base teórica está nas preferências do consumidor via função de utilidade individual. $\mathrm{O}$ método de Preço Hedônico considera que o preço de um bem ou serviço é função de vários atributos, cujo efeito é possível de ser isolado do seu preço. Aplicação usual deste método ocorre nas análises sobre mudanças de preços de residências como função de várias características, com destaque para aquelas que retratem a qualidade ambiental.

\section{INDIVIDUALIZAÇÃO DA COBRANÇA: TAXA DE DRENAGEM URBANA}

A utilização de uma taxa de drenagem é uma forma de sinalizar para o usuário a existência de valor nos serviços de drenagem. Existem custos na provisão da drenagem urbana que variam principalmente em função da parcela de solo impermeabilizada. E a drenagem urbana gera benefícios sociais positivos, valores de uso e não uso.

A definição adequada da tarifa ou taxa possibilita que esta cumpra algumas funções, o que depende do objetivo a ser alcançado com a receita tarifária. Seis funções podem ser enumeradas (Andrade, 1998):

1. cobrir os custos de produção dos serviços;
2. gerar os recursos financeiros para a expansão da rede de serviços;

3. sinalizar para o consumidor a escassez relativa da oferta;

4. papel racionalizador do consumo;

5. remunerar o capital utilizado na produção;

6. ser instrumento da política social do governo.

As funções 1 e 2 visam a sustentabilidade financeira dos serviços: ressarcimento dos custos de investimento, operação e manutenção necessários à prestação dos serviços, além de gerar um excedente para ampliação dos mesmos. Estes investimentos são geralmente rebatidos ao longo de um período de amortização propiciado por empréstimos levantados para financiamento das obras.

A terceira e a quarta função estão associadas à eficiência econômica: nos serviços de drenagem, ao estímulo ao uso racional do solo a fim de evitar a impermeabilização desnecessária deste.

$\mathrm{Na}$ demanda pelo serviço de drenagem aspectos como necessidade, preferência e restrição orçamentária não são integralmente considerados pelo usuário, pois o serviço é percebido como "dado": existe uma oferta única, permanentemente disponível, independente do nível de consumo. Por ser tão presente, e na ausência de uma cobrança específica pelo seu uso, quando eficaz, ele tende até a ser ignorado pelos usuários.

Esta é uma situação que, além de não inibir a impermeabilização desnecessária do solo, estimula o "carona": como o serviço é obrigatoriamente ofertado no mesmo nível para todos os usuários, utilizálo mais significa, indiretamente, pagar menos por ele. O carona é facilmente observável na vida cotidiana: é o sonegador de tributos ou aquele que faz ligações clandestinas para acesso aos serviços públicos e privados. O sonegador sabe que os seus impostos, individualmente, não afetam o nível de bens e serviços públicos. Por outro lado, ao sonegar, ele aumenta a sua renda para o consumo privado. "Deixar o outro fazer" é ótimo na ótica individual, mas ineficiente do ponto de vista da sociedade como um todo.

Em suma, a dissociação entre o consumo individual e o pagamento por este consumo - ou os custos gerados por este consumo - não incentiva a racionalização da demanda, não há um esforço para evitar a impermeabilização do solo. Em conseqüência, os consumos agregados desses serviços tendem a ser superiores aos que seriam necessários.

A quinta função da tarifa é remunerar adequadamente os agentes econômicos envolvidos no 
empreendimento. A receita gerada pela prestação dos serviços constitui parte da composição do capital a ser empregado no investimento e define a maior ou menor necessidade de recursos financeiros complementares.

A sexta função, a utilização da taxa sobre os serviços públicos como instrumento de redistribuição de renda, está ligada a alguns objetivos sociais mais amplos (Andrade, 1998):

- assegurar um padrão mínimo de vida a todos os indivíduos (objetivo da base mínima);

- contribuir para diminuir os problemas da distribuição de renda, objetivo a ser perseguido por qualquer política governamental, qualquer que seja seu objetivo principal (objetivo de equalização subsidiária);

- reforçar a igualdade de oportunidades entre os indivíduos (objetivo da meritocracia).

No Brasil, uma das principais formas de utilização social da tarifa ou taxa sobre os serviços públicos ocorre via concessão de subsídios dos usuários de maior poder aquisitivo para os de menor, assim como dos grandes para os pequenos usuários. A Companhia de Saneamento de Minas Gerais - COPASA/MG, por exemplo, utiliza a sistemática em cascata na definição da sua estrutura tarifária. Existem tarifas diferenciadas segundo blocos de consumo de água e segundo a categoria do usuário - residencial, pública, comercial, industrial ou residencial com tarifa social. Algumas tarifas estão acima da tarifa média (subsidiadores) e outras abaixo (subsidiados).

\section{Definição jurídica da taxa}

A escolha de uma taxa como forma de remuneração da drenagem urbana tem respaldo não apenas na esfera econômica, mas também no Direito Administrativo. Segundo Bastos (1994), os serviços públicos

prestados sob a forma de fruição "uti universi" são financiados pelos próprios cofres públicos, que se abastecem fundamentalmente de impostos. Por outro lado, a prestação "uti singuli" cobra-se diretamente do usuário, exceto quando previsto em lei sua prestação gratuita, o que não é regra, mesmo porque não atende ao princípio da boa política tributária, que consiste em repartir tanto quanto possível os ônus com aqueles que se beneficiem do serviço. Sendo estes divisíveis, parece a melhor política cobrá-los. (grifo nosso) (Bastos, op.cit., p.167)

A cobrança pelos serviços públicos pode ser via tarifa - ou preço público - ou taxa. A primeira opção é utilizada quando o serviço implica alternativa, quando o indivíduo pode escolher entre usá-lo ou não. É o que ocorre nos serviços de transporte público, telefonia ou distribuição de energia elétrica domiciliar.

A segunda alternativa, a cobrança via taxa, está presente nos serviços públicos com utilização obrigatória pela população, independente de seu uso efetivo. Basta apenas que os serviços tenham sido disponibilizados à sociedade pela administração pública. Nos termos da Constituição Federal (1988), artigo 145, inciso II:

Art. 145. A União, os Estados, o Distrito Federal e os Municípios poderão instituir os seguintes tributos:

(...)

II. Taxas, em razão do exercício do poder de policia ou pela utilização, efetiva ou potencial, de serviços públicos específicos e divisíveis, prestados ao contribuinte ou postos a sua disposição.

A divisibilidade é a característica essencial dos serviços para que ocorra a sua individualização (uti singuli) e, por conseguinte, a cobrança via taxa ou tarifa. Embora o sistema de drenagem seja "imposto" à população, é possível estimar a contribuição de cada terreno no escoamento pluvial lançado às redes. A indivisibilidade ocorre na oferta e não na demanda. Pode-se identificar o usuário do serviço e a magnitude do uso. O mesmo não ocorre na segurança pública ou na iluminação de praias. São serviços voltados para uma pluralidade de pessoas, onde não se consegue determinar qual seria mais diretamente aquinhoada.

A conclusão é que a remuneração por taxa dos serviços de drenagem, que têm caráter obrigatório e divisibilidade de demanda, parece adequada do ponto de vista tributário. Ressalta-se que a taxa, ao contrário da tarifa, é um tributo, portanto sujeito às especificidades do Direito Tributário.

\section{Definição metodológica da taxa}

No início do artigo foi apontado que uma cobrança pelos serviços que defina o preço igual ao custo marginal não é viável em grande parte dos serviços de utilidade pública, entre eles, a drenagem 
urbana de águas pluviais. Formas alternativas de precificação podem ser utilizadas, seguindo objetivos de eficiência econômica ou sustentabilidade financeira. Algumas utilizam o custo marginal como critério de cobrança, porém em uma base mais ampla, com a incorporação de custos sociais, um horizonte temporal maior ou a viabilidade financeira do empreendimento. Outras têm a disposição marginal a pagar ou o custo médio como referência.

\section{- Preço igual ao custo marginal social}

Esta forma de cobrança define o preço igual ao custo marginal. Mas este não se restringe à mudança do custo de operação e manutenção com a variação no número de usuários. Os custos sociais decorrentes daquela atividade também são incorporados no cálculo, como problemas de drenagem, aumento da insegurança em relação ao risco de inundações, poluição da água ou as enchentes a jusante.

A adoção de uma tarifa via custo marginal apresenta restrições, pois pode implicar em perdas financeiras para a prestadora dos serviços de drenagem (custo médio maior do que o custo marginal, mesmo o social). Outra dificuldade é a quantificação, em termos monetários, da ampla gama de custos incorporados ao cálculo da tarifa.

- Preço igual ao benefício marginal

Esta alternativa de cobrança ocorre nos bens públicos com consumo não rival e custos marginais bastante baixos ou nulos. A provisão do bem deve ocorrer, pois gera benefícios marginais positivos, e esta envolve custos fixos que precisam ser remunerados. A cobrança via benefício marginal aloca o bem de acordo com o retorno econômico para cada usuário. O seu preço efetivamente se iguala ao seu valor para o usuário. Em termos matemáticos,

$$
p_{i}=\partial u / \partial q
$$

Onde,

$\mathrm{p}_{\mathrm{i}}=$ preço cobrado do usuário $\mathrm{i}$

$\mathrm{u}=$ utilidade do bem para o usuário i

$q$ = quantidade consumida do bem pelo usuário i

A relação $\partial u / \partial q$ reflete a disposição marginal a pagar pelo consumo do bem.

Esta alternativa tem complicadores. Primeiramente é necessário conhecer os benefícios marginais individuais, o que apresenta dificuldades. Como o consumo é não excludente, pois se trata de bem público, os indivíduos, a fim de pagarem menos ou nada pela demanda do bem, ou mesmo por desconhecimento, nem sempre estão dispostos a revelar o valor de seus benefícios. O resultado é uma arrecadação subotima de recursos que pode não ser suficiente para financiar a provisão do serviço.

Nos serviços de drenagem urbana, esta opção poderia ser utilizada em obras locais de controle de inundações quando os benefícios são mais bem percebidos e os beneficiários estão mais sensíveis aos danos. No caso de uma cobrança generalizada e continuada pelos serviços clássicos de drenagem para fins de financiamento haveria dificuldades para sua operacionalização e implementação.

\section{- $\quad$ Regra Ramsey ou Regra de Preços Públicos}

Esta regra, que pode ser utilizada em firmas multiproduto ou quando é feita uma discriminação de preços sobre serviços ou consumidores, possibilita a criação de uma estrutura de preços que leve à maximização do bem-estar social com a garantia de receita que cubra os custos.

Segundo a regra de Ramsey, para se alcançar o objetivo financeiro e de eficiência, deve-se adicionar na cobrança via custo marginal uma margem sobre este custo na proporção inversa da elasticidade-preço da demanda dos consumidores. Logo, quanto menor for a elasticidade-preço da procura pelo serviço, maior deve ser o preço cobrado em relação ao seu custo marginal. Matematicamente,

$$
\mathrm{p}_{\mathrm{j}}-\frac{\frac{\partial \mathrm{c}_{\mathrm{j}}}{\partial \mathrm{x}_{\mathrm{j}}}}{\mathrm{p}_{\mathrm{j}}}=\alpha\left(\frac{1}{\left|\varepsilon_{\mathrm{j}}\right|}\right)
$$

Onde,

$\mathrm{p}_{\mathrm{j}}=$ preço do bem $\mathrm{j}$

$\partial \mathrm{c}_{\mathrm{j}} / \partial \mathrm{x}_{\mathrm{j}}=$ custo marginal na produção do bem $\mathrm{j}$

$\alpha=$ constante de proporcionalidade que reflete a diferença relativa entre benefícios e custos marginais

$\varepsilon_{\mathrm{j}}=$ elasticidade-preço da demanda pelo bem $\mathrm{j}$

A somatória destes desvios com os custos marginais deve cobrir integralmente os custos de produção do serviço.

A alternativa de Ramsey, com qualidades financeiras e de eficiência econômica (evita-se o sobrelucro), pode ser ineficaz do ponto de vista social, 
pois elasticidades menores levam a tarifas maiores. Os usuários com menor nível de renda pagariam maiores tarifas pelos serviços públicos do que os de maior rendimento, pois, por terem menores opções de consumo, usualmente possuem uma demanda menos elástica. O mesmo ocorreria com os serviços essenciais em relação aos supérfluos (Andrade, 1998). Lanna (2001) mostra o exemplo da elasticidade-preço da procura de água pela indústria. Ela tende a ser maior do que a do usuário doméstico, basicamente pelas opções tecnológicas de suas funções de produção que permitem uma maior variabilidade na demanda de água. Por conseguinte, os preços da cobrança de abastecimento doméstico seriam maiores do que os do usuário industrial. Além disso, é necessária informação detalhada sobre as demandas individuais dos bens e as elasticidadespreço de demanda dos serviços de drenagem urbana são de difícil quantificação.

\section{- Custos de Longo Prazo}

As metodologias que utilizam análises de longo prazo pressupõem mudanças no tamanho da unidade produtiva, com movimentos de retração ou expansão. Têm como base o custo marginal ou o custo médio de longo prazo. No primeiro caso, trabalha-se com as variações futuras do custo por unidade adicional produzida. No segundo, utiliza-se não a variação, mas o custo total por quantidade produzida.

Esta forma de cobrança apresenta vantagens por sinalizar o comportamento futuro do custo e do valor econômico do bem, garantido a receita para expansão dos serviços. A principal desvantagem são exatamente as incertezas sobre o desempenho futuro do projeto, principalmente com o desenvolvimento tecnológico.

\section{- Preço igual ao Custo Médio}

No Brasil, onde praticamente inexistem informações precisas sobre a demanda dos serviços de drenagem, com análises de elasticidades e de benefícios marginais, e sem experiências de medição do consumo individual dos serviços e a sua cobrança, existem muitas dificuldades na utilização metodológica das alternativas marginalistas - alternativas que contemplam primordialmente a eficiência econômica. Por outro lado, metodologias de longo prazo só são possíveis em um horizonte de planejamento onde ocorrem mudanças nos fatores fixos de produção, no "tamanho" do sistema de drenagem.
Como solução alternativa define-se uma taxa equivalente ao custo médio de produção, priorizando o financiamento do sistema com a recuperação dos custos associados ao mesmo. Este é o procedimento usual na cobrança dos serviços de abastecimento de água. Ao priorizar o financiamento, a eficiência é negligenciada, pois quaisquer que sejam os gastos, inclusive as perdas, eles são rateados entre os consumidores.

O Quadro 1, em anexo, sintetiza as alternativas de cobrança discutidas.

\section{A cobrança pela drenagem urbana via custo médio dos serviços}

A definição de uma taxa sobre os serviços de drenagem associada ao custo médio torna obrigatório o claro conhecimento dos custos associados a sua prestação. Os custos dos serviços de drenagem urbana para fins de financiamento podem ser divididos principalmente em dois:

a) Custos de capital: custo de implantação do sistema de micro e macrodrenagem (planejamento, projeto, construção etc). Envolve grande aporte de recursos para cobri-lo. É o custo inicial de prestação dos serviços, quando o sistema ainda não está em operação. Pode ser considerado fixo, pois é determinado a partir do dimensionamento do sistema que se baseia na perspectiva de demanda máxima.

b) Custo de manutenção do sistema: limpeza de bocas-de-lobo e redes de ligação, vistorias em estruturas de macrodrenagem (e.g.: canais, bueiros, dissipadores de energia, etc.) e recuperação de patologias estruturais. São custos associados ao desgaste da rede, à deposição de lixo e sedimentos no sistema, aos problemas de projeto etc. As evidências são de que a magnitude deste custo tem relação estreita com as velocidades de escoamento e com a qualidade da água transportada pela estrutura (Belo Horizonte, 2001). Obviamente, o fator tempo é um componente fundamental no planejamento da manutenção.

A soma destes dois componentes do custo representa o custo total (CT) de prestação dos serviços de drenagem urbana. O custo médio (Cme) determinado em relação ao volume de escoamento urbano é: 
Quadro 1 - Modelos de Cálculo Tarifário

\begin{tabular}{|c|c|c|c|}
\hline $\begin{array}{l}\text { Determinação } \\
\text { de Tarifas } \\
\text { (Taxas) }\end{array}$ & Situação & Vantagens & Problemas \\
\hline $\begin{array}{l}\text { = Custo Margi- } \\
\text { nal }\end{array}$ & Mercado Concorrencial & $\begin{array}{l}\text { Maximização do bem-estar } \\
\text { social }\end{array}$ & $\begin{array}{l}\text { Falta de interesse ou impossibi- } \\
\text { lidade de definir a tarifa a este } \\
\text { nível: monopólio natural; ma- } \\
\text { ximização de lucros por uma } \\
\text { empresa monopolista; tarifas } \\
\text { com funções redistributivas etc. }\end{array}$ \\
\hline $\begin{array}{l}\text { = Benefício } \\
\text { Marginal }\end{array}$ & $\begin{array}{l}\text { - Consumo não rival } \\
\text { - Custo marginal nulo e } \\
\text { custo fixo positivo } \\
\text { - Provisão monopolística }\end{array}$ & $\begin{array}{l}\text { Aloca-se o bem de acordo } \\
\text { com o retorno econômico } \\
\text { para cada usuário. A capaci- } \\
\text { dade de pagamento do con- } \\
\text { sumidor é central na meto- } \\
\text { dologia. }\end{array}$ & $\begin{array}{l}\text { - Omitir os verdadeiros benefí- } \\
\text { cios. Incentivo ao carona. }\end{array}$ \\
\hline $\begin{array}{l}\text { Ramsey Prices. } \\
\text { A tarifa apro- } \\
\text { xima-se do } \\
\text { custo marginal. }\end{array}$ & $\begin{array}{l}\text { Discriminação de preços } \\
\text { sobre serviços ou sobre } \\
\text { consumidores. }\end{array}$ & $\begin{array}{l}\text { Maximização do bem-estar } \\
\text { social com garantia de recei- } \\
\text { ta que cubra os custos. }\end{array}$ & $\begin{array}{l}\text { - As tarifas podem ser indesejá- } \\
\text { veis do ponto de vista distribu- } \\
\text { tivo. } \\
\text { - Requer informações detalha- } \\
\text { das sobre as demandas indivi- } \\
\text { duais. }\end{array}$ \\
\hline = Custo Médio & $\begin{array}{l}\text { - Necessidade de cobrir } \\
\text { custos (custos marginais } \\
\text { pequenos e custos fixos } \\
\text { muito elevados) }\end{array}$ & $\begin{array}{l}\text { - Definição de tarifa não } \\
\text { abusiva que garanta a viabili- } \\
\text { dade financeira da firma. } \\
\text { - Relativa facilidade de im- } \\
\text { plementação. }\end{array}$ & $\begin{array}{l}\text { - Privilegia-se a sustentabilidade } \\
\text { financeira. A maximização do } \\
\text { bem-estar social não é garanti- } \\
\text { da. } \\
\text { - Determinação dos verdadeiros } \\
\text { custos da firma. }\end{array}$ \\
\hline $\begin{array}{l}=\text { Custo Margi- } \\
\text { nal de Longo } \\
\text { Prazo }\end{array}$ & $\begin{array}{l}\text { Eficaz, principalmente } \\
\text { quando, com o aumento } \\
\text { da escala de produção, } \\
\text { os custos marginais } \\
\text { aumentarem de forma } \\
\text { mais acelerada do que } \\
\text { os custos médios do } \\
\text { sistema. }\end{array}$ & $\begin{array}{l}\text { Forma dinâmica de tarifação, } \\
\text { com a incorporação de cená- } \\
\text { rios futuros de planejamen- } \\
\text { to. Possibilidade de maximi- } \\
\text { zação do bem-estar social no } \\
\text { longo prazo. }\end{array}$ & $\begin{array}{l}\text { - Dificuldades para conhecer os } \\
\text { custos marginais de longo } \\
\text { prazo (incertezas, mudanças } \\
\text { tecnológicas etc.). }\end{array}$ \\
\hline $\begin{array}{l}\text { = Custo Médio } \\
\text { de Longo } \\
\text { Prazo }\end{array}$ & $\begin{array}{l}\text { Forma dinâmica de } \\
\text { tarifação, com a incor- } \\
\text { poração de cenários de } \\
\text { planejamento futuros. }\end{array}$ & $\begin{array}{l}\text { Forma dinâmica de tarifação, } \\
\text { com a incorporação de cená- } \\
\text { rios futuros de planejamen- } \\
\text { to. Possibilidade de garantir } \\
\text { recursos financeiros para } \\
\text { expansão do sistema no } \\
\text { longo prazo. }\end{array}$ & $\begin{array}{l}\text { - Dificuldades para conhecer os } \\
\text { custos de longo prazo (incerte- } \\
\text { zas, mudanças tecnológicas } \\
\text { etc.). }\end{array}$ \\
\hline
\end{tabular}

$$
\mathrm{Cme}=\mathrm{CT} /\left(\sum_{\mathrm{vj}}+\mathrm{v}_{\mathrm{v}}\right)
$$

Onde:

$\mathrm{v}_{\mathrm{j}}=$ volume lançado pelo imóvel $\mathrm{j}$

$\sum \mathrm{v}_{\mathrm{j}}=$ volume produzido na área de lotes coberta pelo sistema

$\mathrm{v}_{\mathrm{v}}=$ volume produzido nas áreas públicas, como vias e praças, coberta pelo sistema

Alternativamente, pode-se relacionar o custo com a parcela de solo impermeabilizada: 


$$
\mathrm{Cme}=\mathrm{CT} /\left(\sum \mathrm{ai}_{\mathrm{j}}+\mathrm{ai}_{\mathrm{v}}\right)
$$

Onde:

$\mathrm{ai}_{\mathrm{j}}=$ área impermeabilizada do imóvel $\mathrm{j}$

$\sum \mathrm{ai}_{\mathrm{j}}=$ parcela do solo impermeabilizada pelos imóveis na área urbana coberta pelo sistema de drenagem

$\mathrm{ai}_{\mathrm{v}}=$ parcela do solo impermeabilizada pelas vias na área urbana coberta pelo sistema

Neste artigo utiliza-se como expressão do custo médio a equação acima, e a partir dela é feito o rateio de custo entre os usuários do sistema.

\section{Parâmetros de Cobrança}

Debo \& Reese (1995) definem algumas bases possíveis para uma taxa básica sobre os serviços de drenagem, sempre com o objetivo de onerar segundo uma estimativa da demanda individual dos serviços:

- área impermeável;

- área impermeável e área bruta;

- área impermeável e porcentagem impermeável;

- área impermeável ponderada por um fator ligado à declividade;

- área bruta e um fator de intensidade de desenvolvimento;

- área bruta com uso extensivo de fatores de modificação.

Como a parcela de solo impermeabilizado é determinante no dimensionamento dos sistemas de drenagem e o principal responsável pela especificidade do escoamento urbano em relação ao escoamento gerado em um ambiente natural, parece apropriado que a cobrança pelos serviços incida sobre a área impermeável da propriedade (equação 4). Uma taxa assim concebida, além de cumprir a função de recuperação dos custos associados aos serviços, incorpora o componente econômico da cobrança, citado anteriormente nas funções três e quatro das taxas.

Em análise sobre as características e impactos de diferentes modalidades de financiamento dos serviços de drenagem, Baptista \& Nascimento (2002) destacam as vantagens de uma taxa que incida sobre a impermeabilização do solo: base física, caráter incitativo e equidade. Mas existem problemas como a dificuldade de implementação, os impactos legais e políticos e a opinião pública.
Alternativamente, pode-se incorporar na cobrança a área bruta da propriedade com a suposição de que a área permeável tem participação não desprezível no volume de escoamento gerado. A participação de ambas as áreas, permeável e impermeável, no cálculo da cobrança deve ser feita com ponderação criteriosa que reflita a contribuição de cada uma no escoamento lançado à rede de drenagem.

Alguns fatores de modificação podem ser incorporados a esta taxa básica: um plano de pagamento para cobrança de residência unifamiliar, uma sobretaxa para bacias específicas que necessitem de maiores investimentos, uma sobretaxa para propriedades localizadas em áreas inundáveis, créditos sobre a taxa em propriedades que possuem sistemas de detenção ou retenção local, fator de desenvolvimento e uso do solo, fator de nível do serviço etc. Estes fatores são usados para garantir a equidade ou para aumentar a facilidade de implementação e gerenciamento da cobrança.

Uma taxa que tenha como objetivo a recuperação dos custos associados ao investimento, se linear, pode ser definida como:

Taxa de drenagem $=\mathrm{p} \times \mathrm{ai}_{\mathrm{j}}$

Onde:

$\mathrm{p}$ = custo médio do sistema por metro quadrado de área impermeável $\left(\mathrm{CT} / \Sigma \mathrm{ai}_{\mathrm{j}}+\mathrm{ai}_{\mathrm{v}}\right)$

$\mathrm{ai}_{\mathrm{j}}=$ área impermeabilizada do imóvel $\mathrm{j}$

Neste caso, o custo é rateado segundo as demandas individuais e os proprietários de imóveis não arcam com o custo relacionado à área impermeável das vias, que fica sob responsabilidade do setor público. A simplicidade desta taxa possibilita que cada usuário compreenda a forma de cobrança e sua base de incidência.

Adicionalmente, pode-se utilizar a tarifação pelo custo do serviço. As tarifas, além de remunerar os serviços, possuem uma margem que proporciona ao investidor uma taxa interna de retorno razoável:

Receita - (despesas + depreciação + impostos) $=\mathrm{s}$ x base de capital

Onde:

Receita = taxa de drenagem + impostos gerais (participação do setor público no financiamento da drenagem urbana devido à impermeabilização das vias)

$\mathrm{s}=$ taxa de remuneração do capital investido (taxa 
interna de retorno)

Base de Capital $=$ investimentos já realizado e em operação ("custo histórico")

Usualmente as tarifas que incidem sobre os serviços de saneamento básico utilizam esta forma de cobrança no Brasil. A definição das tarifas pelo regime de custo pelo serviço está presente no Decreto no 82.587 de 1978 , que cria normas para as tarifas das Companhias Estaduais de Saneamento Básico, ainda hoje em vigor em várias delas.

Outra questão que envolve a remuneração dos serviços de drenagem é a possível necessidade de cobrança de um valor mínimo sobre os proprietários de lotes não ocupados, uma vez que tenha sido disponibilizado o sistema. Simulações com o custo total dos serviços, formas de rateio e o impacto em novas urbanizações ou urbanizações existentes são importantes na definição da taxa sobre o lote não ocupado.

\section{CONCLUSÃO}

Compreender as características econômicas dos serviços de drenagem urbana é uma forma de discutir o seu valor e custo para o usuário, algo negligenciado pela suposição de que o serviço de drenagem é um bem público indivisível. Mas, se na oferta dos serviços clássicos de drenagem a indivisibilidade está clara, o mesmo não ocorre na demanda, onde é possível estimar o volume de escoamento lançado na rede de drenagem oriundo de cada terreno.

Identificar o usuário individual e sua demanda pelos serviços, com a utilização da área impermeável de cada propriedade como parâmetro, possibilita uma forma mais justa de rateio dos custos da drenagem urbana. A discriminação deste rateio poderia vir sob a forma de taxa, o que não significa o aumento do nível geral de tributos ou da receita tributária. A taxa pode vir sob a forma de um acréscimo no IPTU cobrado ou de uma redução no mesmo conforme se impermeabilize o terreno mais ou menos do que a média. Procura-se apenas sugerir uma alternativa de financiamento da drenagem urbana, com ganhos de transparência, racionalidade econômica e eficiência tributária.

Ao associar explicitamente custo e área impermeabilizada, a taxa pode incitar ao uso racional do solo urbano e sinalizar claramente que a urbanização implica custos sociais.

As bases conceituais e microeconômicas pa- ra a criação de uma taxa são um primeiro passo para a análise de alternativas de financiamento da drenagem urbana. Já existe estudo com simulações envolvendo a definição da magnitude da taxa de drenagem urbana, considerando os custos de implantação e manutenção do sistema clássico de drenagem em uma bacia hidrográfica hipotética, e qual seu impacto na renda familiar.

\section{AGRADECIMENTOS}

Este projeto foi apoiado pela Financiadora de Estudos de Projetos com recursos do Fundo Setorial CT-HIDRO (FINEP-CT-HIDRO-URBAGUA). $O$ segundo autor beneficiou-se de uma bolsa de produtividade em pesquisa do $\mathrm{CNPq}$.

\section{REFERÊNCIAS}

ANDRADE, Thompson A. Tarifas das Utilities em um Contexto de Liberalização/ Privatização. In: REZENDE, Fernando; PAULA, Tomás Bruginski (coord.). Infra-Estrutura: Perspectivas de Reorganização e Financiamento. Brasília: IPEA, 1998.

BAPTISTA, Márcio B.; NASCIMENTO, Nilo O. Aspectos Institucionais e de Financiamento dos Sistemas de Drenagem Urbana. RBRH-Revista Brasileira de Recursos Hídricos, Porto Alegre, RS, v. 7, n.1, p. 29-49, jan/mar 2002.

BASTOS, Celso Ribeiro. Curso de Direito Administrativo. São Paulo: Saraiva, 1994.

BELO HORIZONTE. Prefeitura Municipal. Plano Diretor de Drenagem de Belo Horizonte. Belo Horizonte, 2001.

DAUN, Margaret C.; CLARK, David. Flood Risk and Contingent Valuation Willingness to Pay Studies: A Methodological Review and Applied Analysis. Technical Report 6. Institute for Urban Environmental Risk Management. Marquette University, Milwaukee, WI, August 2000.

DEBO, Thomas N.; REESE, Andrew J. Municipal Storm Water Management. Lewis Publishers: Boca Raton, 1995.

LANNA, Antonio Eduardo. Economia e Recursos Hídricos: Parte I. Universidade Federal do Rio Grande do Sul, Instituto de Pesquisas Hidráulicas, Programa de Pós-Graduação em Recursos Hí- 
dricos e Saneamento Ambiental, 2001 (apostila de curso).

VARIAN, Hal R. Microeconomia: Princípios Básicos. Rio de Janeiro: Campus, 1997.

Charging for Urban Storm Water Drainage: Conceptual Basis and Microeconomic Principles

\section{ABSTRACT}

In an environment of growing public budget restrictions, new solutions to finance urban storm water drainage services are discussed. As an alternative to traditional local property taxes there could be a specific charge for drainage services via a drainage tax. This tax could mean better allocation and socially fairer distribution of costs. Nevertheless, the economic peculiarities of urban drainage, as a matter of public interest and offered as a monopoly, make it difficult to create a specific tax. Adopting a theoretical and conceptual approach, this article discusses these peculiarities, the possibility of establishing a drainage tax based on economic theory and the most appropriate methodology for this purpose.

Keywords: storm water drainage; drainage tax; water charges. 